\title{
INSTRUMENTOS DE AVALIAÇÃO DE CURSOS: indícios que definem a qualidade de um curso de graduação na perspectiva do SINAES
}

\author{
ADENIZE COSTA ACIOLI \\ Universidade Estadual de Alagoas - UNEAL. Doutora em Linguística Aplicada \\ Análise do Discurso. Pró-Reitora de Graduação. Orcid: 0000-0002-9488-1800. \\ E-mail: adenize.acioli@gmail.com
}

\section{MARIA ANTONIETA ALBUQUERQUE DE OLIVEIRA}

Universidade Federal de Alagoas - UFAL Doutora em Educação. Orcid: 0000-0001-8312-1542.

E-mail: mariaantonieta07@gmail.com 


\section{INSTRUMENTOS DE AVALIAÇÃO DE CURSOS: indícios que definem a qualidade de um curso de graduação na perspectiva do SINAES}

O artigo se propõe à análise crítica dos instrumentos de avaliação externa de cursos de graduação, do sistema federal de ensino superior, produzidos sob a ótica da política de avaliação determinada pelo Sistema Nacional de Avaliação da Educação Superior - SINAES - na intenção de extrair os atributos que identificam um curso como sendo de qualidade, na perspectiva dos indicadores oficiais determinados pelos referenciais mínimos, definidos pela Secretaria de Ensino Superior do Ministério da Educação SESu/MEC. Nesta perspectiva, foram considerados os instrumentos de avaliação de cursos de graduação editados entre 2004 e 2017, para fins de reconhecimento e/ou renovação de reconhecimento.

Palavras-chave: Instrumentos de Avaliação de Cursos de Graduação. Indicadores de Qualidade. Ensino Superior.

\section{COURSE EVALUATION TOOLS: indicators that define the quality of an undergraduate course from the perspective of SINAES}

The article proposes a critical analysis of the external evaluation instruments of undergraduate courses of the federal higher education system, produced from the perspective of the evaluation policy determined by the National Higher Education Evaluation System - SINAES - in order to extract the attributes that identify a course as being of quality, from the perspective of official indicators determined by the minimum standards, defined by the Higher Education Secretariat of the Ministry of Education - SESu / MEC. In this perspective, the assessment tools of undergraduate courses published between 2004 and 2017 were considered for recognition and / or renewal of recognition.

Keywords: Undergraduate Assessment Instruments. Quality Indicators. Higher Education.

\section{HERRAMIENTAS DE EVALUACIÓN DEL CURSO: indicadores que definen la calidad de un curso de pregrado desde la perspectiva del SINAES}

El artículo propone un análisis crítico de los instrumentos de evaluación externa de los cursos de pregrado del sistema federal de educación superior, producidos desde la perspectiva de la política de evaluación determinada por el Sistema Nacional de Evaluación de la Educación Superior (SINAES) para extraer los atributos. que identifican un curso como de calidad, desde la perspectiva de los indicadores oficiales determinados por las referencias mínimas, definidas por la Secretaría de Educación Superior del Ministerio de Educación - SESu / MEC. En esta perspectiva, las herramientas de evaluación de los cursos de pregrado publicados entre 2004 y 2017 se consideraron para reconocimiento y / o renovación de reconocimiento.

Palabras-clave: Instrumentos de Evaluación de Pregrado. Indicadores de Calidad. Educación Superior. 


\section{INSTRUMENTOS DE AVALIAÇÃO DE CURSOS: indícios que definem a qualidade de um curso de graduação na perspectiva do SINAES}

\section{Introdução}

A proposta de trabalho foi a de analisar criticamente os instrumentos de avaliação externa de cursos de graduação, do sistema federal de ensino superior, editados pelo Instituto Nacional de Estudos e Pesquisas Educacionais Anísio Teixeira - INEP, entre 2004 e 2017, e elaborados em colaboração entre a Comissão Nacional de Avaliação da Educação Superior - CONAES - e a Diretoria de Estatísticas e Avaliação da Educação Superior - DEAES. As Diretrizes Curriculares Nacionais - DCN -, os referenciais mínimos de qualidade definidos pela Secretaria de Ensino Superior do Ministério da Educação - SESu/MEC - e os princípios e diretrizes do Sistema Nacional de Avaliação da Educação Superior - SINAES - serviram de referência para sua formulação. O objetivo foi o de extrair dos documentos os indícios que classificam um curso de graduação em relação à qualidade. Ou seja, o que identifica que um determinado curso de graduação possa ser considerado como tendo qualidade em referência aos padrões oficiais?

O foco da análise foram os indicadores e/ou grupo de indicadores de cada dimensão e/ou categoria considerando apenas os conceitos que classificam cada um deles: 3 (três), 4 (quatro) e 5 (cinco). O primeiro, definido como o referencial mínimo e o último como o referencial máximo em termos de qualidade, expressa de diferentes formas em diferentes instrumentos. Os conceitos 1 (um) e 2 (dois), neste entendimento, foram excluídos do estudo por não serem considerados como sinalizadores de qualidade e, uma vez atribuídos aos indicadores/grupos de indicadores e dimensões/ categorias, podem comprometer o conceito final do curso, rebaixando-o para um patamar inferior ao aceitável como mínimo para aprovação para fins de autorização e reconhecimento ou sua renovação. Assim sendo, o trabalho destaca e analisa nos instrumentos de avaliação de cursos, editados no período de tempo 2004-2017 os indícios que qualificam um curso superior como de qualidade.

\section{Instrumentos de Avaliação - Referenciais de Qualidade}

Nesta perspectiva, foram identificados os seguintes instrumentos de avaliação de curso: 07 (sete) de autorização; 07 (sete) de reconhecimento; 02 (dois) de reconhecimento e renovação de reconhecimento; 02 (dois) de renovação de reconhecimento e 05 (cinco) de autorização, reconhecimento e renovação de reconhecimento, e as respectivas portarias que lhes dão respaldo legal, editados no 
período de tempo 2004-2017, considerado pelo estudo. Do total de 23 instrumentos, há aqueles específicos.

Tabela 1. Instrumentos de Avaliação de Cursos por área de conhecimento

\begin{tabular}{|l|l|l|}
\hline \multirow{2}{*}{ CURSOS } & \multicolumn{2}{c|}{ NATUREZA } \\
\cline { 2 - 3 } & \multicolumn{1}{|c|}{ Autorização } & \multicolumn{1}{c|}{ Reconhecimento } \\
\hline Direito & 2008 & 2009 \\
\hline Medicina & 2010 & 2010 \\
\hline Pedagogia & - & 2010 \\
\hline Superior de Tecnologia & 2010 & 2009 e 2010 \\
\hline
\end{tabular}

Fonte: Site do INEP

Desses observa-se, uma variação em relação à nomenclatura adotada nos mesmos que não apontam para cursos em especial.

Tabela 2. Instrumentos de Avaliação de Cursos por especialidade ${ }^{1}$

\begin{tabular}{|l|l|l|l|l|l|}
\hline \multirow{2}{*}{ CURSOS } & \multicolumn{5}{|c|}{ NATUREZA } \\
\cline { 2 - 7 } & Autorização & Reconhecimento & $\begin{array}{c}\text { Renovação de } \\
\text { reconhecimento }\end{array}$ & $\begin{array}{c}\text { Reconhecimento } \\
\text { e renovação de } \\
\text { reconhecimento }\end{array}$ & Único \\
\hline $\begin{array}{l}\text { Bacharelado } \\
\text { e licenciatura }\end{array}$ & 2007,2010 & $2008,2009,2010$ & - & - & 2011 \\
\hline Graduação & 2017 & - & 2008,2010 & 2006,2017 & 2012, \\
\hline
\end{tabular}

Fonte: Site do INEP

As edições de 2011, 2012 e 2015 - "cursos de bacharelado, licenciatura e superiores de tecnologia" e "cursos de graduação", são instrumentos únicos não se distinguindo quanto à natureza ou à especificidade. No primeiro caso, tratando-se de autorização avalia-se a previsão de implementação dos aspectos referidos no Projeto Pedagógico de Curso - PPC - e demais documentos

1 A Portaria Ministerial n.02 de 5 de janeiro de 2009 dispõe sobre o reconhecimento de cursos de bacharelado e licenciatura na modalidade presencial e traz em anexo um extrato do instrumento de avaliação. No entanto, não foi localizada cópia impressa desta edição.

\section{plupais


apresentados pela instituição de ensino - IES. No tocante ao reconhecimento e/ou sua renovação, considera-se se os mesmos aspectos estão devidamente institucionalizados, regulamentados e implantados. Para atender às especificidades, recorre-se ao NSA ("não se aplica") quando o curso não se encontra em conformidade para ser pontuado na área de conhecimento e/ou modalidade em processo de avaliação.

Considerando o universo acima referido, foram submetidos à análise crítica apenas os instrumentos de avaliação de curso para fins de reconhecimento e/ou renovação de reconhecimento, nomeados como "cursos de bacharelado e licenciatura" e "cursos de graduação", por se entender serem nestas situações que se conceituam os cursos em termos de qualidade efetivada, enquanto a autorização pontuaria tão somente a potencialidade e a expectativa de qualidade a ser alcançada pela concretização das condições de implantação de um projeto pedagógico a ser desenvolvido por um corpo social, dada as condições de infraestrutura e os recursos previstos.

Não importando o regime acadêmico da IES (universidade, centro universitário ou faculdade) os cursos devem obrigatoriamente solicitar o reconhecimento por uma comissão de avaliação externa, quando cumprida entre 50 e $75 \%$ da carga horária total prevista em seu Projeto Pedagógico $^{2}$. Uma vez concedido, o mesmo é automaticamente renovado a cada ciclo avaliativo, caso o curso mantenha Conceito Preliminar de Curso (CPC) igual ou superior a 3 (três). A exigência de renovação de reconhecimento, por processo de avaliação externa, ocorre, caso o mesmo seja igual ou inferior a 2 (dois). Importante observar que este resulta de cálculo aritmético complexo envolvendo, entre outros indicadores, o conceito obtido pelos alunos concluintes no Exame Nacional de Desempenho do Estudante - ENADE. Infere-se, portanto, que a qualidade atestada em um determinado curso poderá ser contestada a cada ciclo avaliativo e não está na dependência apenas dos indicadores das dimensões avaliativas definidas pela CONAES e pontuadas nos instrumentos de avaliação externa de curso.

Um primeiro olhar permitiu extrair dos instrumentos selecionados seus elementos estruturantes - dimensões, categorias e indicadores - e identificar os termos de escala aplicados aos aspectos a serem avaliados. Consideraram-se, também, nas dimensões, os atributos valorizados em cada indicador. Desta feita, foi possível compor um quadro que facilitasse a análise comparativa e crítica do material, sempre em referência aos instrumentos editados em 2006, com exceção da edição de 2017 por apresentar mudanças substanciais em sua estrutura e formulação.

2 Art. 31 da Portaria Normativa n. 23 de 21/12/2018. 
O art. $4^{\circ}$ da Lei 10.861/2004 - Lei do SINAES dispõe que a avaliação dos cursos de graduação tem por objetivo "identificar as condições de ensino oferecidas aos estudantes, em especial as relativas ao perfil do corpo docente, as instalações físicas e a organização didático-pedagógica”. Em seu Parágrafo $1^{\circ}$ afirma que "utilizará procedimentos e instrumentos diversificados, dentre os quais obrigatoriamente as visitas por comissões de especialistas das respectivas áreas do conhecimento".

Em consonância com o dispositivo legal, as Portarias MEC - 300, de 30 de janeiro, e 563, de 21 de fevereiro de 2006, instituíram os Instrumentos de Avaliação Externa e o de Avaliação de Cursos de Graduação do SINAES, respectivamente, que passariam a disciplinar a concretização das ações propostas pela política de avaliação, conforme já expresso no documento "Sistema Nacional de Avaliação da Educação Superior (SINAES): bases para uma nova proposta da educação superior", e reproduzido como "Apresentação da 1". Edição," na $4^{\mathrm{a}}$ edição ampliada do livro "SINAES: da concepção à regulamentação":

Desse processo avaliativo, articulado com mecanismos regulatórios do Estado decorrem ações de fomento e medidas de natureza corretiva e planos de expansão qualificada que assegurem o desenvolvimento da Educação Superior em patamares compatíveis com metas de curto e longo prazos, de acordo com diagnósticos de necessidades nacionais e regionais, de avanço do conhecimento e de atuação acadêmico profissional (BRASIL, 2007, p. 15).

Em sua decorrência foram identificados três documentos similares ${ }^{3}$ editados em março, maio e junho do mesmo ano com "Apresentação"4 do, então, Ministro da Educação, Fernando Hadad, que os definem enquanto instrumentos únicos a ser...,

(...), utilizado para o reconhecimento e renovação de reconhecimento dos cursos de Bacharelado, Licenciatura e Tecnológicos, nas modalidades presencial e a distância. Neste sentido, tem como características a abrangência e a flexibilização necessárias para assegurar avaliação fidedigna destes cursos, respeitando suas peculiaridades contempladas nas DCN de cada curso, a diversidade regional e a identidade institucional. ${ }^{5}$

No mesmo texto há a preocupação em conceituar os termos: categorias, grupo de indicadores, indicadores e critérios, com a finalidade de orientar os avaliadores e as próprias IES. Neste

3 Apenas a edição de maio apresenta um sistema de numeração de seus itens diferenciado dos demais. 4 Instrumento de Avaliação de Curso de Graduação, Brasília, DF, março de 2006, Apresentação.

5 Instrumento de Avaliação de Curso de Graduação, Brasília, DF, março de 2006, Apresentação.

\section{plurais}


sentido, categorias "são agrupamentos de grandes traços ou características referentes aos aspectos do curso sobre as quais se emite juízo de valor e em seu conjunto, expressam sua totalidade". Grupo de indicadores é "o conjunto de características comuns usadas para agrupar, com coerência e lógica, evidências da dinâmica acadêmica dos cursos". Indicadores são "os aspectos (quantitativos e qualitativos) que possibilitam obterem evidências concretas que, de forma simples ou complexa, caracterizam a realidade dos múltiplos elementos institucionais que retratam". Critérios "são os padrões que servem de base para comparação, julgamento ou apreciação de um indicador". ${ }^{6}$

A leitura atenta dos referidos instrumentos, que não se diferenciam em termos de conteúdo, permite observar que estão subsidiados por concepções e princípios de avaliação de curso no âmbito do SINAES, em relação ao Projeto Pedagógico de Curso - PPC -, ao Projeto de Desenvolvimento Institucional - PDI - e às Diretrizes Curriculares - DCN - específicas de cada área de formação profissional, bem como suas articulações. As edições de 2006 são as únicas que apresentam o esquema de uma matriz orientadora do processo avaliativo e suas categorias, expressão adotada, então, em relação às dimensões. Estruturam-se a partir de três categorias/dimensões: Organização didático pedagógica; Corpo docente, corpo discente e corpo técnico administrativo e Instalações físicas, que se organizam em grupos de indicadores (apenas em 2006), a serem avaliados através de critérios para atribuição de conceitos. As categorias/dimensões, por sua vez, possuem pesos diferenciados: 40,35 e 25 , respectivamente, enquanto que dentro da uma mesma categoria, os grupos de indicadores possuem pesos iguais. Nas edições de 2011 e 2012, a nomenclatura das dimensões foi revista passando a segunda a se denominar Corpo Docente e Tutorial e a terceira, Infraestrutura, assim como os pesos atribuídos: 40, 30, 30 para autorização e 30, 30, 40 para reconhecimento e sua renovação.

Uma quarta dimensão - Requisitos Legais - de caráter estritamente regulatório, portanto não pontuada para a conceituação do curso, mas com indicadores de caráter obrigatório por força de leis e/ou resoluções cuja presença, no âmbito do curso, devem ser constatadas pelos avaliadores externos, foram integrados aos instrumentos de avaliação na edição de 2008 e se tornaram mais numerosos a partir de então. Indicadores imprescindíveis são os definidos por legislação em vigor, portanto, de caráter obrigatório. Há outros aos quais pode ser atribuída a situação de NSA quando remetem às especificidades de determinados cursos ou modalidades. Nestes, destacam-se: a não exigência de Trabalho de Conclusão de Curso (TCC) para os cursos superiores de tecnologia e a 6 IB, Apresentação. 
da pesquisa para as faculdades e centros universitários; a comprovação da experiência de trabalho na educação básica para as licenciaturas e a formação e experiência em tutoria para os da modalidade a distância. O curso de Medicina é o que se apresenta com maiores exigências específicas em termos de aspectos a serem avaliados. A edição de 2017 apresenta substanciais alterações em relação aos indicadores.

Faz-se importante observar que o nível de exigências para todos os cursos é sempre crescente em relação aos aspectos descritos para serem avaliados em cada indicador. Quanto aos Requisitos Legais, até a edição de 2015, se revestiram de alto nível de exigência, tendo a IES de se pronunciar em função da não constatação da presença de alguns deles por ocasião da visita da comissão de avaliação externa? ${ }^{7}$.

Consta, ainda, dos instrumentos de avaliação uma contextualização da IES e do curso e uma síntese preliminar a serem redigidas pelos avaliadores. Ao final de cada categoria abre-se espaço para uma análise qualitativa, embora nem sempre com a mesma orientação. O sentido, entretanto, aponta para a sinalização de forças/potencialidades; fragilidades/pontos que requerem melhorias e recomendações. Cabe aos avaliadores, também, apresentarem os argumentos que justifiquem os conceitos atribuídos aos indicadores pelos avaliadores, ou como consta das edições de 2006, um parecer analítico final da Comissão de Avaliação Externa e/ou para um relato global da dimensão, expressões que variam a cada edição.

A descrição dos instrumentos de 2006 se faz pertinente por terem servido de modelo para os demais, muito embora se evidencie a preocupação com a revisão dos mesmos no sentido de minimizar a subjetividade do olhar dos avaliadores externos. Assim, na "Apresentação" da Portaria Ministerial 1.081, de 19 de agosto de 2008, Fernando Hadad se refere à:

...compreensão da avaliação como um processo dinâmico, que exige mediação pedagógica permanente, impõe ao Ministério da Educação a responsabilidade de rever periodicamente os seus instrumentos e procedimentos de avaliação, de modo a ajustá-los aos diferentes contextos e situação que se apresentam no cenário da educação superior e torná-los elementos balizadores da qualidade que se deseja para a graduação.

E conclui afirmando que:

7 O espaço para pronunciamento da IES está presente nas edições de 2012 e 2015. 
Com o novo instrumento de Avaliação de Cursos de graduação o INEP está apto a implementar esta etapa do processo avaliativo integrado do SINAES, assegurando a oferta de cursos de educação superior com qualidade acadêmica e o compromisso social com o desenvolvimento do País ${ }^{8}$.

O Documento anexo à Portaria acima referida, editado em setembro de 2008, preserva as dimensões até então contempladas nos instrumentos de avaliação anteriores e explicita, apenas, o referencial mínimo de qualidade (conceito 3 ) a ser observado em cada um dos indicadores, sempre expresso em referência a sua adequação ao aspecto em análise. Ao final de cada dimensão abre-se o espaço para a apreciação qualitativa em termos de "Considerações sobre a dimensão".

A partir de 2008, por determinação da Portaria Ministerial 02, de 05 de janeiro de 2009, os instrumentos passam a ser disponibilizados na versão on-line no sistema e-MEC. Desta forma, os editados em dezembro de 2008, foram revisados em 2010, conservando a estrutura dos anteriores em termos de dimensões, indicadores e critérios, agora nomeados como de análise.

Em 2011, foi postada, no site do INEP", uma edição dos "Instrumentos de Avaliação de Cursos de Bacharelado, Licenciatura, e Superiores de Tecnologia", com a característica de se tratar de um documento único para atendimento às situações de autorização, reconhecimento e renovação de reconhecimento para cursos presenciais e na modalidade à distância.

Nesta perspectiva, um novo instrumento de avaliação substituiu os anteriores incorporando os cursos em suas diversas modalidades e áreas de conhecimento, resguardando as especificidades quando necessário. Mantiveram-se as mesmas dimensões, porém, com pesos diferenciados em se tratando de autorização ou reconhecimento e sua renovação. Assim, para a primeira situação, a Infraestrutura passou a ter peso 40 e as demais, peso 30; para reconhecimento e renovação de reconhecimento o maior peso recai sobre a Organização didático pedagógica. Há um maior quantitativo de indicadores a serem pontuados segundo critérios de análise e o espaço para o relato global de cada dimensão. As fontes de consulta para os avaliadores externos foram acrescidas das informações prestadas pela IES no formulário eletrônico disponibilizado no sistema e-MEC. Observe-se que, por se tratar de um único instrumento servindo para todas as situações de avaliação de curso, os critérios de análise são pontuados em função de uma análise sistêmica e global da previsão (caso de autorização) ou da constatação de sua implantação e regulamentação (caso de reconhecimento/ renovação de reconhecimento).

8 Instrumento de Avaliação dos Cursos de Graduação. Apresentação, Brasília, set. 2008.

9 Consulta feita ao site do INEP em dezembro de 2019 não constatou a presença desse instrumento de avaliação. 
$\mathrm{Na}$ intenção de se revisar constantemente os instrumentos, a Portaria 1.741, de 21 de dezembro de $2011 \mathrm{em}$ seu Art. $1^{\circ}$ resolve: "Aprovar em extrato os indicadores do Instrumento de Avaliação de Cursos de Graduação nos graus de tecnólogo, de licenciatura e de bacharelado para as modalidades: presencial e a distância, anexo a esta Portaria", dando oportunidade a que, a partir de maio de 2012, fosse inserido no site do INEP uma nova edição, mantendo as características da anterior em termos de estrutura e termos de escala. Os indicadores, entretanto, são mais explícitos em função dos aspectos a serem comprovados pelos avaliadores. Crescem, também, as exigências em relação ao curso de Medicina.

A Portaria 670, de agosto de 2017, embasa legalmente novas edições - uma de autorização e outra de reconhecimento e renovação de reconhecimento, essa contemplada nesse artigo, por apresentar substanciais mudanças estruturais, embora mantenha a configuração das dimensões Organização Didático-Pedagógica, Corpo Docente e Tutorial e Infraestrutura.

A edição 2017 ao formular os termos de escala atribuindo maior precisão às categorias de análise a serem evidenciadas em cada indicador sinaliza a intenção do almejado controle da subjetividade do olhar dos avaliadores.

$\mathrm{O}$ atual instrumento traz novos indicadores em relação as edições anteriores, tendo alguns sido alterados; outros suprimidos e/ou sofreram junção, resultando em um documento mais conciso, muito embora ainda persista a subjetividade que se pretendia eliminar, notadamente em relação a Dimensão 2 ao tratar de indicadores relacionados à titulação e experiência de magistério superior e/ou de ensino a distância do corpo docente e tutorial. Antes esses indicadores eram avaliados em bases quantitativas; agora passam a sê-lo considerando aspectos qualitativos de nem sempre fácil comprovação.

A dimensão Requisitos Legais deixa de ser objeto de observação pela comissão de avaliadores externos e passa a ser contemplada em outras etapas de tramitação dos processos. Ainda assim, os aspectos legais e regulatórios não deixam de se fazer presentes no corpo do documento atrelados a critérios de análise de alguns indicadores como, por exemplo, a política de Acessibilidade (reduzida a oferta da disciplina de LIBRAS) a ser observada em relação à estrutura curricular do curso, e as políticas de Educação Ambiental, Direitos Humanos, Relações Étnico-raciais e História e Cultura Afro-brasileira, africana e indígena que devem estar incluídas nos conteúdos curriculares.

\section{plurais}


O texto de "Apresentação" do Documento justifica a necessidade de se proceder à análise, revisão e adequação dos instrumentos, por um Comitê Gestor - eminentemente oficial, subsidiado por uma Comissão Consultiva - que congrega parceiros de instituições ligadas à educação, com o propósito de "democratizar e tornar mais transparente" os procedimentos avaliativos. Entre esses parceiros encontram-se: a Associação das Universidades Comunitárias (ABRUC); o Fórum das Entidades Representantes do Ensino Superior Particular (FÓRUM); a Associação Brasileira de Educação a Distância, (ABED), o Fórum Nacional de Pró-reitores das Universidades Estaduais e Municipais (ForGRAD), a Associação Brasileira de Reitores das Universidades Estaduais e Municipais (ABRUEM) e a Associação Nacional dos Dirigentes das Instituições Federais de Ensino Superior (ANDIFES).

Ainda, o mesmo documento afirma que o aporte para as alterações realizadas está na legislação pertinente, em novas resoluções legais, em estudos estatísticos, metas do Plano Nacional de Educação, em demandas da sociedade civil organizada e da comunidade acadêmica, na incorporação de sugestões dos especialistas do BASis e no diálogo permanente entre INEP e a Secretaria de Ensino Superior - SERES.

As dimensões foram ponderadas diferentemente, considerando as versões instrumento de autorização e instrumento de reconhecimento e renovação de reconhecimento, este com atribuição de maior peso à Dimensão 2 - Corpo Docente e Tutorial (40) e enquanto as demais ficaram com pesos iguais (30). Um glossário serve a explicitar aos avaliadores externos o significado dos termos constantes do instrumento.

Atenção especial deve ser dada na análise dos instrumentos de avaliação de curso são os termos de escala, pinçados à cada edição, que servem à comprovação da presença dos indicadores, exprimindo ideias de quantidade: não existente, insuficiente e suficiente a serem atribuídos aos conceitos 1,2 e 3, respectivamente. Já para os conceitos 4 e 5 , há sempre um viés mais tendente ao qualitativo: bom/bem e muito bom/muito bem, até o emprego dos termos "plenamente" e "excelente", presentes a partir de 2008 até o documento de 2015, esses últimos, de conotação claramente qualitativa.

\section{plurais}




\title{
Instrumentos de avaliação e os indícios de Qualidade
}

Faz-se importante, então, introduzir a discussão sobre os termos “qualidade" ou, melhor ainda, "qualidade acadêmica" em referência direta ao discurso oficial aplicado aos cursos de graduação.

Temos como aceito que "qualidade" em referência direta à educação é conceito que se reveste de polissemia e varia em função do sujeito que profere o discurso. Em estreita observação, porém à política adotada pelo SINAES, pode ser referenciada às dimensões que servem de análise às condições de oferta dos cursos de graduação, quais sejam: Organização didático pedagógica, Corpo docente, corpo discente e corpo técnico administrativo/Docente e tutorial e Instalações físicas/Infraestrutura,

Seria, então, o caso de se questionar que atributos, em cada indicador das diferentes dimensões que compõem os instrumentos de avaliação, poderiam, uma vez satisfeitos os referenciais mínimos, serem pontuados/evidenciados em nível de qualidade acadêmica?

Revisita-se, mais uma vez, os documentos oficiais para tentar identificar o que aos olhos da política educacional seriam atributos de qualidade e, em última instância, sua manifestação/evidência em grau de excelência, uma vez introduzido este termo de escala nos instrumentos de avaliação.

O alcance da qualidade das ações acadêmico-administrativas dos cursos depende, portanto, do quadro docente, do corpo técnico-administrativo, dos projetos pedagógicos de cursos, além da infraestrutura física e logística e do ambiente educacional. A exigência da qualidade comporta múltiplos aspectos e o objetivo primordial das medidas adotadas no momento da avaliação deve induzir à melhora no desempenho dos cursos.

A leitura atenta dos instrumentos facilita identificar que constatações de natureza acadêmico-administrativas poderiam permitir aferir a qualidade intrínseca a cada curso, expressas nas relações a serem estabelecidas face aos critérios de análise dos indicadores das dimensões avaliativas.

Em relação à dimensão Organização didático pedagógica valoriza-se: a adequação da proposta do curso às demandas de ordem política, econômica e social considerando o contexto local e regional; a inserção e a implantação das políticas institucionais de ensino, pesquisa e extensão no âmbito do curso; a coerência entre as competências e o perfil de egresso definidos nas diretrizes

\author{
plupais


curriculares da área de formação profissional do curso com os objetivos, os conteúdos curriculares e a bibliografia sugerida nas ementas das disciplinas. Atribui-se importância ainda à coerência entre a concepção metodológica expressa no PPC e as práticas de ensino e de avaliação da aprendizagem e do curso que deve prover um currículo flexível, oferecendo condições de interdisciplinaridade e enriquecido com a presença da relação teoria/prática, do estágio supervisionado, do trabalho de conclusão de curso (TCC) e as atividades complementares, todas estas atividades acadêmicas devidamente regulamentadas e institucionalizadas.

Importante observar, entretanto, em relação ao perfil do egresso, que o valor atribuído à formação para a cidadania, indicador presente nas edições de 2006, foi omitido nas demais, não sendo substituído por outro com teor semelhante ou no mesmo sentido.

A edição de 2017 recupera e atribui importância as experiências de formação profissional que o curso oferece em consonância com o perfil do egresso estabelecido nas DCN, não atentando para a formação para a cidadania. Assim, as políticas institucionais, os objetivos, a estrutura e os conteúdos curriculares e a metodologia devem estar voltadas fundamentalmente para a concretização de um egresso afinado com o mercado de trabalho.

A dimensão Corpo docente, discente e técnico administrativo/Corpo docente e tutorial enfatiza, enquanto aspectos a serem valorizados, a atuação, participação, qualificação, compromisso e experiência profissional dos sujeitos na gestão e na docência do curso, tais como: coordenador, docentes e, a partir de 2010, os membros dos Núcleos Docentes Estruturantes - NDEs, que ganham maior relevo na edição mais recente dos instrumentos, passando a lhes ser cobrada uma atuação mais efetiva na concepção, acompanhamento e avaliação do curso. A experiência é computada em relação à atuação docente no ensino superior, mas exigida, também, na área de formação profissional, na intenção de aferir o domínio do conhecimento do professor para além do plano meramente teórico.

Neste sentido, por exemplo, nos cursos de licenciatura é cobrada aos docentes a comprovação de experiência na Educação Básica. Infere-se, pois, que a competência do professor deve ser mensurada, entre outros atributos, em um discurso qualificado, alimentado pela prática. $\mathrm{O}$ mesmo critério se aplica aos docentes de todas as áreas de conhecimento e modalidades de curso. 
Ainda, na mesma dimensão, para além destes atributos a serem avaliados, de caráter mais qualitativo, as edições anteriores a de 2017, observava-se a exigência da presença de um percentual otimizado de docentes titulados em cursos de pós-graduação stricto senso, bem como a articulação entre estes, o regime de trabalho e o quantitativo de vagas autorizadas para a oferta do curso, aspectos não tão relevantes no atual instrumento de avaliação.

Quanto às Instalações físicas/Infraestrutura os requisitos são no sentido da disponibilidade aos docentes, discentes e técnicos administrativos de ambientes de estudo, de práticas e de trabalho dotadas de condições de conforto, conservação e higiene e recursos tecnológicos compatíveis com as atividades acadêmicas neles desenvolvidas, além de equipamentos específicos suficientes para a realização das atividades de práticas e pesquisa em laboratórios especializados, em conformidade com a natureza dos cursos. A intenção é comprovar se os objetivos propostos e as competências enunciadas no PPC são possíveis de se concretizar com as condições físicas presentes e disponibilizadas para viabilidade do curso.

Um indicador observado com muito cuidado em relação a esta dimensão se refere ao acervo bibliográfico, a ser mensurado em perspectiva qualitativa e quantitativa e que passa a considerar e valorizar a perspectiva da facilitação de acesso aos acervos virtuais. É nesta perspectiva que se retoma as palavras de Hadad ao apresentar os instrumentos de avaliação de curso no ensejo de “... torná-los elementos balizadores da qualidade que se deseja para a graduação" e analisando a série histórica iniciada em 2006, elucida-se a intenção de se promover a indução de aspectos considerados importantes para o alcance da qualidade acadêmica que se almeja, pois a revisão periódica dos indicadores traduz-se na intenção de provocar o afunilamento do olhar investigativo dos avaliadores para a comprovação mais efetiva dos atributos desejáveis de serem alcançáveis.

Infere-se, pois, que uma vez os cursos avaliados demonstrem ter, em sua maior parte, alcançado tais aspectos, há que se elevar o nível de exigências de forma a garantir que a qualidade seja sempre um desafio proposto pela SESu/MEC e uma meta a ser cumprida pelas IES. O emprego do termo de escala "excelência" encontra assim sua razão de ser para aplicação aos indicadores que tenham respondido para além do satisfatório às exigências requeridas em cada dimensão, sempre devidamente evidenciadas.

\section{plurais


A partir do momento que os termos de escala utilizados nos instrumentos de avaliação de curso do INEP se propõem a pontuar a excelência em relação aos cursos de graduação seria interessante observar o que distingue "qualidade" de "excelência" em nosso sistema de ensino superior.

A adoção do termo de escala "excelência" (conceito 5) para a pontuação máxima de um indicador, pressupõe que o mesmo seja considerado não apenas como plenamente atendido em todos os aspectos exigidos pelo referencial de qualidade oficial (conceito 4), mas que se revista de efetividade e eficácia, portanto, exceda a qualidade acadêmica desejada, para situar-se em patamar mais elevado. Então, não basta satisfazer a exigência de se comprovar a presença dos aspectos referidos nos indicadores, mas de apresentá-los dotados de atributos que ultrapassem o que seria desejável em termos de qualidade acadêmica.

A aferição do que se pretende, a partir de 2017, como qualidade acadêmica, substitui o que antes se expressava por excelência pela expressão Muito Bom, embora continue a ser a meta a ser alcançada pelo sistema de regulação proposto pelo SINAES. Essa agora se expressa referenciada aos termos: "atende", "expressa", "articula", "promove" e outros mais que se aplicam aos indicadores de cada dimensão e que devem estar presentes e evidenciados em graus crescentes em cada indicador até ser considerado Bom ou Muito Bom. Assim, mantém-se os conceitos 1 e 2 como insatisfatórios ou parcialmente insatisfatórios; 3 satisfatório; 4 bom e 5 muito bom, ou seja, os dois últimos expressam o teor de qualidade/excelência auferida pelo curso.

Por "evidência" entende-se a confirmação de um fato verificado in loco pela comissão de avaliação externa a luz dos critérios de análise e que devem ser substanciados por informações pertinentes, necessárias à complementar a decisão pela atribuição do conceito. Este deve levar em conta todos os atributos do critério de análise que se apresentam grifados em cada indicador. Consideram-se como fontes de evidências as informações inseridas no e-MEC, entrevistas com diferentes sujeitos da IES ligados ao curso, a análise de seus documentos e a verificação das condições de infraestrutura.

Na mesma perspectiva, faz-se importante observar o caráter fortemente indutivo da dimensão 4 - Requisitos Legais -, determinando a obrigatoriedade da adoção e implantação das políticas educacionais uma vez devidamente regulamentadas. A exemplo, convém citar a criação do NDE, a princípio de existência restrita aos cursos de Direito e de Medicina, por força da Portaria 147, de 2007, mas informalmente cobrado aos demais cursos, até sua implantação em caráter universal pelo Parecer CONAES 01/10. A mesma observação se aplica aos demais indicadores que passaram a 
compor esta dimensão até a edição de 2015. Sua supressão em 2017, embora não tenha eliminado de vez as exigências de cumprimento legal das políticas que regem o ensino superior, com certeza não favorece a implantação das mesmas, uma vez que diluídas por levemente referenciadas a poucos indicadores e não mais sendo objeto de cobrança pelos avaliadores externos, pouco contribuição poderão dar a fomentação de ações a elas pertinentes.

O que se observa é que a exigência de se alcançar o mais elevado grau de qualidade, qual seja o de excelência/muito bom, atentando às prerrogativas da indução faz com que as IES passem a compor, frente à iminência da presença de uma comissão de avaliação externa, um cenário maquiado que, em muitas das vezes, não encontra correspondência em seu fazer cotidiano, mas confirma o desejável. Assim sendo, sugere-se uma pseudo qualidade frente às diferentes realidades avaliadas, situação que se pretende atenuar com a exigência de se justificar de forma mais contundente a evidência da comprovação dos critérios de análise de cada indicador, introduzido na edição de 2017 dos instrumentos de avaliação de curso. Considerar que um dado curso possui qualidade em relação aos aspectos solicitados, não significa que realmente a tenha efetivamente, ainda que respondendo adequadamente ao desafio posto. O que se avalia, nesta circunstância, é não é tão somente a capacidade do curso se adequar ao modelo ideal desenhado pelo atendimento quantitativo e qualitativo aos indicadores das dimensões aos quais deve se regular, mas sua comprovação através de fatos e práticas evidenciadas e documentadas.

\section{Considerações Finais}

Apreender o discurso da qualidade tendo como pano de fundo a educação superior se traduz em tarefa árdua da qual já tínhamos conhecimento ao iniciarmos este trabalho. No entanto, direcionamos nosso olhar para os instrumentos de avaliação externa de cursos de graduação para reconhecimento e renovação de reconhecimento, editados pelo INEP, entre 2006 e 2017, para tentar extrair os atributos que conceituam um curso superior de graduação como sendo de qualidade na perspectiva do discurso oficial.

O atendimento às exigências dos referenciais de qualidade oficiais em grau de plenitude, excelência ou conforme os termos de escala constantes dos instrumentos de avaliação seria se compor à imagem de um modelo ideal, abstração que não passa de um constructor referencial de atributos altamente desejáveis a serem demonstrados pelos cursos de graduação das diferentes categorias e instituições de ensino superior. Neste sentido, um curso de qualidade seria aquele que conseguisse satisfazer evidenciando plenamente a prática de todos os atributos das três dimensões

\section{plurais}


e ainda atendesse aos requisitos legais, agora bastante atenuados e diluídos, oriundos das determinações impostas ao sistema federal de ensino.

Vale destacar que, a qualidade também passa pela comprovação das condições de viabilizar um Projeto Pedagógico a ser implantado sob a responsabilidade de um corpo social apto a conduzir uma dinâmica acadêmica coerente e lógica dada às condições de infraestrutura e recursos disponíveis.

Assim, considerando a possibilidade do alcance da qualidade que se almeja, percebe-se que o atendimento a este patamar se caracteriza como uma situação de exceção no cômputo geral dos conceitos atribuídos aos cursos superiores. Portanto, um curso em nível de excelência, ainda se configura como um curso oferecido por poucas IES e para poucos alunos, a confirmação desta condição revela um andar na contramão da democratização da educação superior, política educacional tão prezada pela sociedade e tão imprescindível para o desenvolvimento político, econômico e sócio cultural do país.

\section{REFERÊNCIAS}

BRASIL. Lei 10.861 de 14 de abril de 2004. Congresso Nacional. Brasília, DF.

BRASIL, Ministério da Educação. Portaria n. 300 de 30 de janeiro de 2006. Brasília, DF. BRASIL, Ministério da Educação. Portaria n. 563 de 21 de fevereiro de 2006. Brasília, DF. BRASIL, Ministério da Educação. Portaria n. 1.081 de 19 de agosto de 2008. Brasília, DF. BRASIL, Ministério da Educação. Portaria n. 02 de 05 de janeiro de 2009. Brasília, DF. BRASIL, Ministério da Educação. Portaria n.741 de 21 de dezembro de 2011. Brasília, DF. BRASIL, Ministério da Educação. Portaria n. 670 de 11 de agosto de 2017. Brasília, DF. BRASIL, Ministério da Educação. Portaria n. 23 de 21 de dezembro de 2018. Brasília, DF. BRASIL, Ministério da Educação, CONAES, INEP, DAES, SINAES. Diretrizes para a avaliação dos cursos de graduação. Brasília, DF, s/d.

BRASIL, Ministério da Educação, CONAES, INEP, DAES, SINAES. Instrumento de avalia- 
ção de cursos de graduação. Brasília, DF, março 2006.

BRASIL, Ministério da Educação, CONAES, INEP, DAES, SINAES. Instrumento de avaliação de cursos de graduação. Brasília, DF, maio 2006.

BRASIL, Ministério da Educação, CONAES, INEP, DAES, SINAES. Instrumento de avaliação de cursos de graduação. Brasília, DF, junho 2006.

BRASIL, Ministério da Educação, CONAES, INEP, DAES, SINAES. Instrumento de avaliação de cursos de bacharelado e licenciatura. Brasília, DF, agosto de 2008. www.inep.gov.br Acesso em 07/12/2019.

BRASIL, Ministério da Educação, CONAES, INEP, DAES, SINAES. Instrumento de avaliação de cursos de bacharelado, licenciatura e superiores de tecnologia. Brasília, $\mathrm{DF}, \mathrm{s} / \mathrm{d}$. www.inep.gov.br Acesso em 07/12/2019.

BRASIL, Ministério da Educação, CONAES, INEP, DAES, SINAES. Instrumento de avaliação de cursos de graduação presencial e a distância. Brasília, DF, maio de 2012. www.inep. gov.br Acesso em 07/12/2019.

BRASIL, Ministério da Educação, CONAES, INEP, DAES, SINAES. Instrumento de avaliação de cursos de graduação presencial e a distância: reconhecimento e renovação de reconhecimento. Brasília, DF, outubro de 2017, www.inep.gov.br Acesso em 07/12/2019.

SINAES - Sistema nacional de avaliação da educação superior: da concepção à regulamentação. - 4 ed. ampl. - Brasília, DF: INEP, 2007.

Enviado em: 20 de janeiro de 2020.

Inserido em: 20 de abril de 2020 .

Esta obra está licenciada com uma Licença Creative Commons Atribuição 4.0 Internacional. 